\title{
Triacylglycerol Composition of Protected Designation of Origin Cheeses During Ripening. Authenticity of Milk Fat
}

\author{
J. Fontecha, ${ }^{1}$ I. Mayo, G. Toledano, and M. Juárez \\ Dpto. de Ciencia y Tecnología de Productos Lácteos, Instituto del Frío (CSIC), C/ José Antonio Novais, \\ 10, Ciudad Universitaria, 28040 Madrid, Spain
}

\begin{abstract}
Triacylglycerol (TAG) composition by carbon number in 2 protected designation of origin cheeses, Mahón (cheese from cow milk) and Manchego (cheese from ewe milk) that were manufactured by 3 different producers was analyzed during cheese ripening using gas chromatography with a short capillary column. The TAG composition at different times during cheese ripening was also analyzed in cheeses from different batches produced at the same plant. Lipolysis levels in the Mahón and Manchego cheeses during ripening were low; free fatty acid values ranged from 2,500 to $4,000 \mathrm{ppm}$ at the end of ripening. The TAG composition did not change significantly during ripening. The TAG values obtained from each cheese sample were substituted into the multiple regression equations that have been proposed to detect foreign fats in milk fat. The values obtained using the equations for bovine (proposed by the European Union) and ovine milk (proposed by our laboratory) were within the normal range. Accordingly, these equations can be considered useful for detecting foreign fat in these cheeses during the ripening period contemplated during this study.
\end{abstract}

Key words: milk fat, cheese, triacylglycerol, foreign fat

\section{INTRODUCTION}

During ripening, triacylglycerols (TAG) undergo hydrolysis in all cheese varieties as a consequence of the action of lipases; this results in the release of partial glycerides, FFA, and other flavor compounds. Lipolysis is an important process in blue cheeses, some Italian hard cheeses, and some cheeses made with rennet pastes (McSweeney, 2004). The presence and the quantities of the different FFA, monoglycerides, and diglycerides depend largely on 1) the degree of lipolytic activity that takes place during ripening, 2) the milk fat substrate present that are TAG at $98 \%$, and 3) the

Received August 1, 2005.

Accepted September 17, 2005.

${ }^{1}$ Corresponding author: jfontecha@if.csic.es length of cheese ripening (Contarini and Toppino 1995; Nájera et al., 1998a,b; Partidario et al., 1998).

Excluding dairy substitutes in which milk fat has purposely been replaced by other fats or vegetable oils, in most countries, the genuine milk origin of the fat in dairy products is strictly regulated.

Analyzing milk fat TAG by carbon number $(\mathbf{C N})$ has been reported to be a more effective method of assessing milk origin (Precht, 1992a) than analyzing the fatty acid composition (Juárez, 1990). Determination of the TAG by gas chromatography employing packed or capillary columns has been used to detect low levels of foreign fats in milk fat (Banfi and Bergna, 1999; Molkentin and Precht, 2000; Naviglio and Raia, 2003; Fuente and Juárez, 2005) and has been proposed by the European Union as an official method of verifying fat purity (EU Commission Regulation No. 213/2001, 2001). Using multiple regression equations based on the TAG composition of cow milk fat, it has been possible to detect levels of foreign fat as low as 2 to $5 \%$ (Timms, 1980; Precht, 1992b; Povolo et al., 1999). Similarly, previous studies to determine the authenticity of goat and ewe milk fat using short capillary column-gas chromatography have been carried out at our laboratory, yielding specific individual equations (Fontecha et al., 1998; Goudjil et al., 2003). These equations for the different types of milk are suitable for confirming the genuineness of milk fat, although they cannot be applied to other dairy products, particularly those in which lipolysis occurs, e.g., cheeses, without previous experimentation studies. Therefore, applicability of these equations to cheeses depends on variations in the TAG composition during ripening (i.e., lipolysis) and on the presence of the diacylglycerol and monoacylglycerol fractions, which co-elute with the low molecular weight TAG.

Although there have been many studies on lipolysis in different types of cheese, mainly FFA analysis (Collins et al., 2003), few have dealt with TAG composition as a means of determining the authenticity of milk fat.

Battelli and Pellegrino (1994) found that lipolysis during prolonged ripening (FFA $>15 \mathrm{mmol} / 100 \mathrm{~g}$ of fat) in several cheeses from cow milk affected the TAG composition by decreasing the low molecular weight TAG through the action of lipases. They concluded that the 
European Union formula was not suitable for detecting foreign fat in milk fat in cheeses that underwent extensive lipolysis. However, Contarini and Toppino (1995) reported little variation in the TAG composition in Gorgonzola cheese during ripening, although the lipolysis level was high.

The object of this study was to ascertain whether the lipolysis that takes place in 2 Spanish protected designation of origin (PDO) cheeses (Mahón and Manchego) affects their TAG composition during ripening and, consequently, to determine the usefulness of the "total formula" equation for examining foreign fat origin in cow milk fat (EU Commission Regulation No. 213/ 2001,2001 ) and the equation for ewe milk fat found at our laboratory (Goudjil et al., 2003).

\section{MATERIALS AND METHODS}

\section{Samples}

Two different semihard PDO cheeses, Mahón and Manchego, were made using cow and ewe milk, respectively, according to the cheese-making procedures for these PDO cheeses as described by González et al. (2002) and Poveda et al. (1999). The cheeses were made at 3 different cheese plants, one artisanal cheese-maker who used raw milk and 2 industrial manufacturers that used pasteurized milk. To carry out the study of changes in TAG composition during ripening, samples of the milk and of the cheeses at 2,60,120, and $180 \mathrm{~d}$ of ripening were taken from one batch of each cheese plant (15 samples; $\mathrm{n}=3$ ). In addition, to study the cheese authenticity, samples of 3 different cheese batches made by each of the 3 cheese plants were also taken at 60,120 , and $180 \mathrm{~d}$ of ripening ( 27 samples; $\mathrm{n}=9$ ).

\section{TAG and FFA Analysis}

The milk fat was extracted according to ISO-IDF (2001). The extracted fat residue was stored frozen in amber vials at $-20^{\circ} \mathrm{C}$ until analysis.

Analysis of TAG was performed on a gas chromatograph equipped with an automatic split/splitless injector (split ratio 1/20; Autosystem, Perkin-Elmer, Beaconsfield, UK) and a flame ionization detector. A capillary column (length $=2.5 \mathrm{~m} ; 35 \%$ dimethyl polysiloxane, $65 \%$ diphenyl polysiloxane, $\mathrm{d}_{\mathrm{f}}=0.1 \mu \mathrm{m}$; Rtx-65 TG, Restek, Bellefonte, PA) was used. Experimental chromatography conditions were an initial oven temperature of $100^{\circ} \mathrm{C}$, a first ramp to $200^{\circ} \mathrm{C}$ at $15^{\circ} \mathrm{C} / \mathrm{min}$, and a second ramp to $355^{\circ} \mathrm{C}$ at $10^{\circ} \mathrm{C} / \mathrm{min}$. Total run time was $17 \mathrm{~min}$. For analysis of the TAG, $0.5-\mu \mathrm{L}$ dilutions of milk fat $(2 \mathrm{mg} / \mathrm{mL})$ in hexane were injected onto the gas chromatograph. Duplicate analyses were performed for each sample. Calibration was carried out using a butter oil of known TAG composition (Certify reference material-CRM 519) from Community Bureau of Reference Materials (Brussels, Belgium).

Free fatty acid determinations were as per Juárez et al. (1992). Lipid extraction was carried out on an acidified cheese slurry (10 g) using ethyl ether, followed by methylation with $20 \%$ tetramethylammonium hydroxide in methanol. Nonanoic acid (C9) as internal standard was used. Free fatty acids were analyzed on a fused silica column $(60 \mathrm{~m} \times 0.22 \mathrm{~mm} \times 0.22 \mu \mathrm{m})$ coated with BPX 70 using Perkin-Elmer 8420 apparatus equipped with a programmable temperature vaporizer injector. Helium was the carrier gas (split ratio $=1 / 20$ ). Oven temperature was held at $70^{\circ} \mathrm{C}$ for $3 \mathrm{~min}$, then raised to $190^{\circ} \mathrm{C}$ at a rate of $13^{\circ} \mathrm{C} / \mathrm{min}$ and held at this temperature for $25 \mathrm{~min}$. The FFA determinations were done in duplicate for each sample.

\section{Statistical Analysis}

The results were analyzed using SPSS version 11.0 (SPSS Inc., Chicago, IL) operating under Windows XP, taking variance over the cheese origin and the entire ripening period into account.

\section{RESULTS AND DISCUSSION}

\section{TAG Composition and FFA Content}

Sixteen peaks were discernible on the chromatograms of the TAG obtained from the samples of the fat from the milk and the cheese, corresponding to TAG with a $\mathrm{CN}$ of 24 , which co-eluted with cholesterol, to 54. Table 1 presents the mean and SD values for the TAG from the milk and the Mahón cheeses made by the 3 different cheese producers over the ripening period considered. The TAG composition for the cow's milk used to manufacture the Mahón cheese was similar to that reported for cow milk previously and exhibited similarities with the range of variation in the individual TAG peaks for bovine milk samples (Precht, 1992a). Variations in the TAG composition among the 3 cheese producers were very small, as evidenced by the resulting standard deviations, except for the high molecular weight CN 52 and CN 54 TAG, as also described by Precht (1992a).

Furthermore, the variations in TAG composition recorded for the cheeses during ripening were not statistically significant $(P<0.05)$. These results were consistent with the FFA contents found at the end of ripening for the 3 batches of Mahón cheese, which were in the range from 2,500 to $4,000 \mathrm{ppm}$, a low level of lipolysis and comparable with the values reported by other researchers (Fuente et al., 1993). 
Table 1. Average triacylglycerol (TAG) composition (weight percentage) of cow's milk and Mahón cheese during ripening $(\mathrm{n}=3)$

\begin{tabular}{|c|c|c|c|c|c|}
\hline \multirow[b]{2}{*}{ TAG } & \multirow[b]{2}{*}{ Milk } & \multicolumn{4}{|c|}{ Cheese (days of ripening) } \\
\hline & & 2 & 60 & 120 & 180 \\
\hline CN $24^{1}+$ cholesterol & $0.47 \pm 0.05$ & $0.38 \pm 0.13$ & $0.41 \pm 0.03$ & $0.40 \pm 0.03$ & $0.38 \pm 0.10$ \\
\hline CN 26 & $0.26 \pm 0.04$ & $0.30 \pm 0.09$ & $0.29 \pm 0.06$ & $0.24 \pm 0.03$ & $0.28 \pm 0.02$ \\
\hline CN 28 & $0.58 \pm 0.08$ & $0.56 \pm 0.03$ & $0.59 \pm 0.05$ & $0.55 \pm 0.04$ & $0.57 \pm 0.07$ \\
\hline CN 30 & $1.10 \pm 0.15$ & $1.18 \pm 0.14$ & $1.12 \pm 0.16$ & $1.06 \pm 0.08$ & $1.13 \pm 0.12$ \\
\hline CN 32 & $2.30 \pm 0.36$ & $2.48 \pm 0.23$ & $2.32 \pm 0.29$ & $2.19 \pm 0.19$ & $2.30 \pm 0.25$ \\
\hline CN 34 & $5.39 \pm 0.67$ & $5.64 \pm 0.22$ & $5.43 \pm 0.66$ & $5.14 \pm 0.42$ & $5.34 \pm 0.61$ \\
\hline CN 36 & $9.91 \pm 0.84$ & $10.14 \pm 0.47$ & $10.00 \pm 0.62$ & $9.60 \pm 0.36$ & $9.95 \pm 0.59$ \\
\hline CN 38 & $12.08 \pm 0.52$ & $12.17 \pm 0.62$ & $12.36 \pm 0.34$ & $11.89 \pm 0.51$ & $12.36 \pm 0.51$ \\
\hline $\mathrm{CN} 40$ & $9.78 \pm 0.64$ & $10.04 \pm 0.92$ & $9.99 \pm 0.58$ & $9.74 \pm 0.71$ & $9.90 \pm 0.54$ \\
\hline CN 42 & $6.30 \pm 0.48$ & $6.58 \pm 0.53$ & $6.29 \pm 0.36$ & $6.14 \pm 0.27$ & $6.16 \pm 0.37$ \\
\hline $\mathrm{CN} 44$ & $5.90 \pm 0.78$ & $6.15 \pm 0.27$ & $5.77 \pm 0.67$ & $5.73 \pm 0.60$ & $5.62 \pm 0.67$ \\
\hline CN 46 & $7.11 \pm 0.98$ & $7.21 \pm 0.38$ & $6.89 \pm 0.83$ & $6.89 \pm 0.88$ & $6.76 \pm 0.69$ \\
\hline $\mathrm{CN} 48$ & $9.22 \pm 1.05$ & $9.21 \pm 0.73$ & $8.97 \pm 0.82$ & $9.16 \pm 0.96$ & $8.98 \pm 0.81$ \\
\hline CN 50 & $11.83 \pm 0.67$ & $11.75 \pm 0.74$ & $11.78 \pm 0.34$ & $12.18 \pm 0.30$ & $11.98 \pm 0.72$ \\
\hline CN 52 & $11.53 \pm 2.02$ & $10.66 \pm 0.99$ & $11.38 \pm 1.43$ & $12.01 \pm 1.15$ & $11.74 \pm 1.46$ \\
\hline CN 54 & $6.23 \pm 2.16$ & $5.55 \pm 1.21$ & $6.41 \pm 1.96$ & $7.07 \pm 1.51$ & $6.55 \pm 1.62$ \\
\hline
\end{tabular}

${ }^{1} \mathrm{CN}=$ Total carbon number of TAG acyl chains.

Table 2 lists the means and standard deviations for the TAG from the milk and the Manchego cheese made by the 3 different cheese producers over the ripening period considered. The TAG composition values for the ewe's milk used were in the same range reported by Goudjil et al. (2003) for ovine milk from 5 herds. There were some variations in the TAG composition among the 3 producers, especially in the high molecular weight CN 50 to CN 54 TAG, although the range of variation was lower than that reported by Goudjil et al. (2003) because only Manchego herds could be used to manufacture the PDO Manchego cheeses used in this study. Still, as in the Mahón cheese, no significant differences $(P<0.05)$ between the milk and the cheeses were found during the ripening time considered. At the end of ripening, the mean total FFA content in the PDO Manchego cheese made by the 3 producers was $4,000 \mathrm{ppm}$, comparable with the values reported by others for this same cheese (Poveda et al., 1999; Pavía et al., 2000). The results for the FFA indicated that lipolysis levels in Manchego cheese are low and were similar to the FFA values in the Mahón cheese. Therefore, it may be concluded that in these cheeses with low lipolysis levels, variations in the TAG composition are minor and that hydrolysis is not selective by TAG length chain.

Moreover, as explained in Materials and Methods, 3 cheeses of the same age but from different manufacturing batches were taken randomly from each of the 3

Table 2. Average triacylglycerol (TAG) composition (weight percentage) of ewe milk and Manchego cheese during ripening $(\mathrm{n}=3)$

\begin{tabular}{|c|c|c|c|c|c|}
\hline \multirow[b]{2}{*}{ TAG } & \multirow[b]{2}{*}{ Milk } & \multicolumn{4}{|c|}{ Cheese (days of ripening) } \\
\hline & & 2 & 60 & 120 & 180 \\
\hline $\mathrm{CN} 24^{1}+$ cholesterol & $0.67 \pm 0.11$ & $0.64 \pm 0.06$ & $0.64 \pm 0.06$ & $0.65 \pm 0.07$ & $0.69 \pm 0.06$ \\
\hline CN 26 & $0.94 \pm 0.15$ & $0.97 \pm 0.11$ & $0.94 \pm 0.10$ & $0.93 \pm 0.12$ & $0.96 \pm 0.09$ \\
\hline CN 28 & $1.79 \pm 0.31$ & $1.82 \pm 0.19$ & $1.77 \pm 0.16$ & $1.71 \pm 0.21$ & $1.77 \pm 0.17$ \\
\hline CN 30 & $2.94 \pm 0.35$ & $3.09 \pm 0.42$ & $3.14 \pm 0.30$ & $3.07 \pm 0.37$ & $3.11 \pm 0.31$ \\
\hline CN 32 & $4.79 \pm 0.49$ & $4.95 \pm 0.50$ & $4.96 \pm 0.44$ & $4.95 \pm 0.42$ & $4.93 \pm 0.48$ \\
\hline CN 34 & $7.04 \pm 0.72$ & $7.22 \pm 0.76$ & $7.31 \pm 0.72$ & $7.24 \pm 0.70$ & $7.32 \pm 0.68$ \\
\hline CN 36 & $9.69 \pm 0.43$ & $7.79 \pm 0.71$ & $9.88 \pm 0.64$ & $9.81 \pm 0.87$ & $9.67 \pm 0.76$ \\
\hline CN 38 & $13.12 \pm 0.53$ & $13.08 \pm 0.35$ & $12.82 \pm 0.57$ & $12.71 \pm 0.64$ & $12.74 \pm 0.50$ \\
\hline $\mathrm{CN} 40$ & $12.93 \pm 0.48$ & $13.06 \pm 0.36$ & $12.89 \pm 0.54$ & $12.83 \pm 0.43$ & $12.73 \pm 0.37$ \\
\hline $\mathrm{CN} 42$ & $10.20 \pm 0.43$ & $10.29 \pm 0.44$ & $10.22 \pm 0.61$ & $10.23 \pm 0.58$ & $10.19 \pm 0.44$ \\
\hline $\mathrm{CN} 44$ & $9.02 \pm 0.43$ & $8.98 \pm 0.27$ & $9.06 \pm 0.52$ & $9.02 \pm 0.55$ & $8.95 \pm 0.49$ \\
\hline CN 46 & $7.00 \pm 0.27$ & $6.86 \pm 0.20$ & $6.91 \pm 0.32$ & $6.96 \pm 0.19$ & $6.95 \pm 0.20$ \\
\hline $\mathrm{CN} 48$ & $5.39 \pm 0.32$ & $5.17 \pm 0.36$ & $5.19 \pm 0.37$ & $5.23 \pm 0.39$ & $5.25 \pm 0.40$ \\
\hline CN 50 & $5.64 \pm 0.66$ & $5.41 \pm 0.89$ & $5.46 \pm 0.95$ & $5.52 \pm 0.99$ & $5.58 \pm 0.83$ \\
\hline CN 52 & $5.77 \pm 1.14$ & $5.54 \pm 1.41$ & $5.59 \pm 1.47$ & $5.76 \pm 1.61$ & $5.85 \pm 1.32$ \\
\hline CN 54 & $3.08 \pm 0.94$ & $3.14 \pm 1.06$ & $3.19 \pm 1.19$ & $3.38 \pm 1.37$ & $3.31 \pm 1.12$ \\
\hline
\end{tabular}

${ }^{1} \mathrm{CN}=$ Total carbon number of TAG acyl chains. 

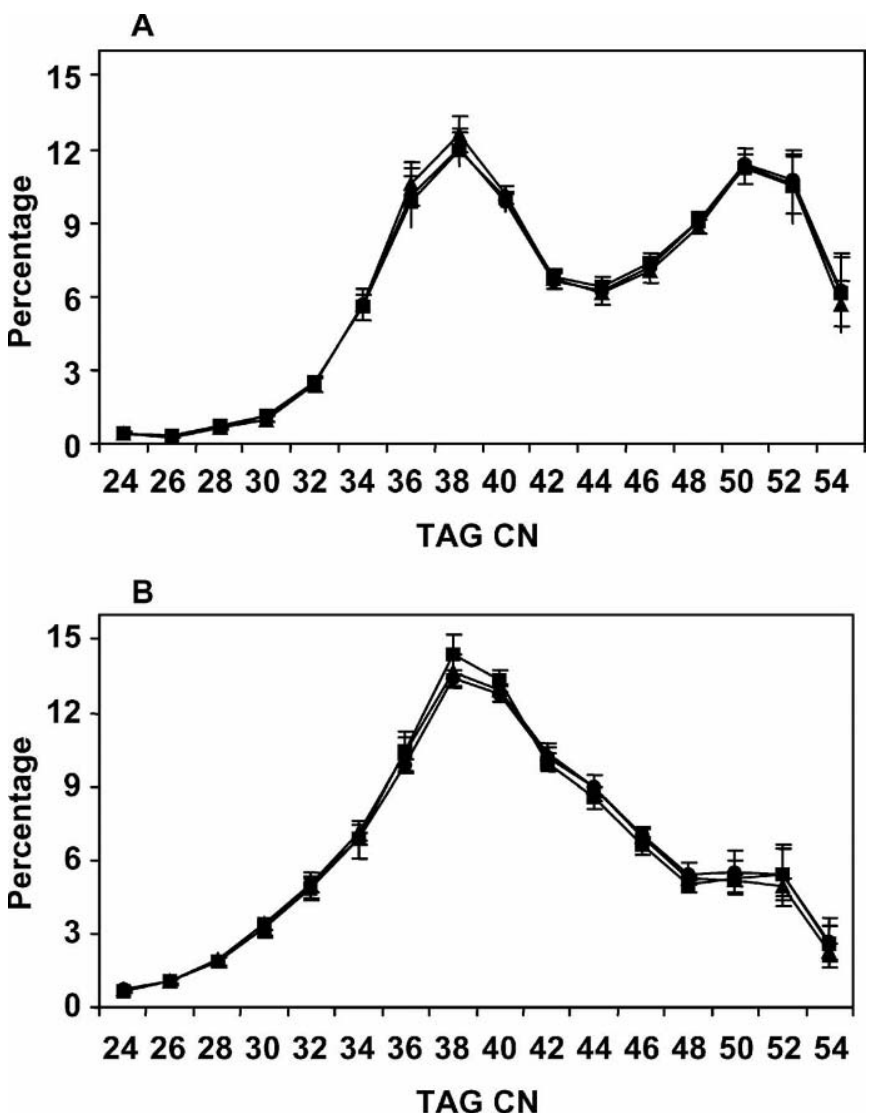

Figure 1. Profile of mean values (percentage and range of variation) of the triacylglycerol composition [triacylglycerol (TAG) with carbon number (CN) from 24 to 54] of Mahón (A) and Manchego (B) cheeses made by 3 different cheese factories and 3 different elaborations each $(\mathrm{n}=9)$ after $60(\square), 120(\bullet)$, and $180(\boldsymbol{\Lambda})$ ripening days.

producers, one a artisanal cheese-making operation using raw milk and 2 industrial producers using pasteurized milk, at 3 ripening times; i.e., 60,90 , and $180 \mathrm{~d}$ (27 cheese samples in all for each type of study cheeseMahón and Manchego). Figure 1 depicts the TAG composition at each ripening time for the studied Mahón (A) and Manchego (B) cheeses. The variations in TAG composition in the cheeses from the 3 different producers were minor with no significant differences $(P<0.05)$ during the ripening period studied. Even for the artisanal cheeses (both Mahón and Manchego), in which lipoprotein lipase is present (McSweeney, 2004), the level of lipolysis observed was very low with FFA contents $<4,000 \mathrm{ppm}$, which is in consonance with the minor changes in TAG composition.

Contarini and Toppino (1995) found no changes in TAG composition in Gorgonzola cheese aged for $105 \mathrm{~d}$ having higher FFA contents (15,000 to $35,000 \mathrm{ppm}$ ) than the cheeses in the present study. Nevertheless, in Serra da Estrela cheese with low FFA levels $(<1,500$ ppm), Partidario et al. (1998) observed lipolysis predominantly of the low molecular weight fatty acids and therefore low molecular weight triglyceride (CN 24 to CN 38) contents were lower in cheese aged for 6 wk than in the milk. Other researchers have reported sizeable variations in TAG composition with decreases in the low molecular weight TAG in cheeses with high lipolysis levels (Nájera et al., 1998a, b; Battelli and Pellegrino, 1994).

Based on the literature results, the FFA levels could not be correlated with the changes in the TAG composition in the 2 types of cheese considered here. This finding is ascribable to differences in the lipolytic agents used in the cheeses (lipoprotein lipase in the raw milk cheeses), the type of rennet used, the enzymatic activity levels of the lactic acid bacteria and accompanying flora, as well as the $\mathrm{pH}$ and temperature during ripening (McSweeney, 2004).

\section{Authenticity of Milk Fat}

The TAG composition data for the cheeses in this study were plugged into multiple linear regression equations of the form:

$$
\Sigma \mathrm{a}_{\mathrm{i}} \mathrm{C}_{\mathrm{i}}=\mathrm{M}+\mathrm{e}
$$

where $\mathrm{i}$ is the $\mathrm{CN}, \mathrm{C}_{\mathrm{i}}$ is the percentage of TAG with $\mathrm{CN}$ $\mathrm{i}, \mathrm{M}$ is a constant for which 100 is pure cow milk, and $\mathrm{e}$ is the random error (Precht, 1992b).

For the Mahón cheese (made with cow milk), the equation used was based on the equations proposed by Precht (1992b) and reported in the official method recently adopted by the European Union (2001) for detecting foreign fats in milk fat, namely:

$$
\begin{aligned}
M= & -2.7575 \times \mathrm{C} 26+6.4077 \times \mathrm{C} 28+5.5437 \\
& \times \mathrm{C} 30 \text { to } 15.3247 \times \mathrm{C} 32+6.2600 \\
& \times \mathrm{C} 34+8.0108 \times \mathrm{C} 40 \text { to } 5.0336 \\
\times & \mathrm{C} 42+0.6356 \times \mathrm{C} 44+6.0171 \times \mathrm{C} 46
\end{aligned}
$$

with a confidence range of $M=95.68$ to 104.32 .

For the Manchego cheese (made with ewe milk), the equation used was based on equations proposed by Goudjil et al. (2003):

$$
\begin{gathered}
M=7.733 \times \mathrm{C} 40+2.428 \times \mathrm{C} 50 \\
+21.392 \times \mathrm{C} 52
\end{gathered}
$$

with a confidence range of $M=98.87$ to 101.25 .

The mean and standard deviations of $M$ obtained when these equations were applied to the TAG composi- 


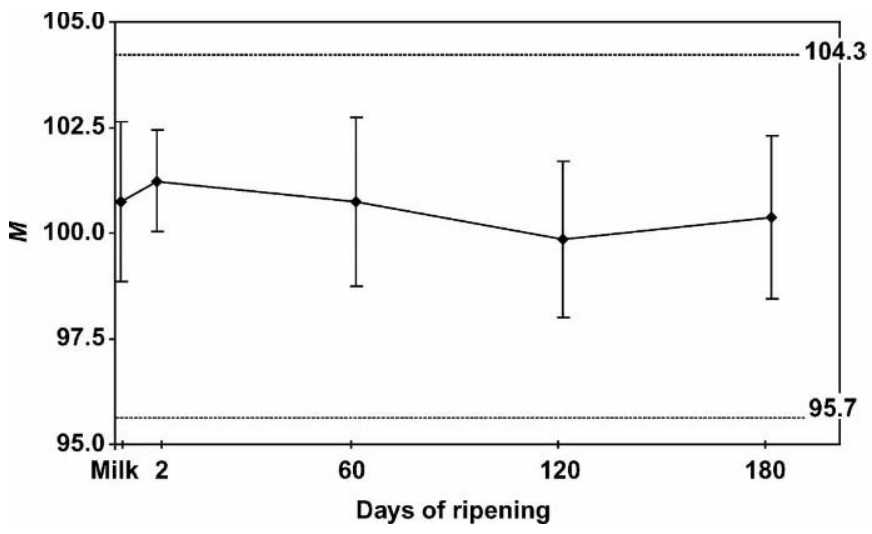

Figure 2. Values of $M$ calculated by substituting the triacylglycerol composition values for milk and Mahón cheeses at ripening period into Equation 1 for cow milk fat proposed in the European Union Regulation. Bold values along the y-axis (dotted lines) refer to the confidence range of the equation. Error bars represent standard deviations ( $\mathrm{n}=3$ for milk and 2-d cheeses; $\mathrm{n}=12$ for 60,120 , and $180 \mathrm{~d}$ of ripening).

$$
\begin{gathered}
M=-2.7575 \times \mathrm{C} 26+6.4077 \times \mathrm{C} 28+5.5437 \times \mathrm{C} 30 \text { to } 15.3247 \\
\times \mathrm{C} 32+6.2600 \times \mathrm{C} 34+8.0108 \times \mathrm{C} 40 \text { to } 5.0336 \\
\times \mathrm{C} 42+0.6356 \times \mathrm{C} 44+6.0171 \times \mathrm{C} 46
\end{gathered}
$$

tion results for all studied samples of the milk and Mahón and Manchego cheeses have been plotted in Figures 2 and 3, respectively.

As expected, in view of the minor variations in the TAG composition recorded during ripening of the Mahón cheese and the relatively broader interval of the total TAG formula value yielded by Equation 1 used for cow milk (95.68 to 104.32; EU Commission Regula-

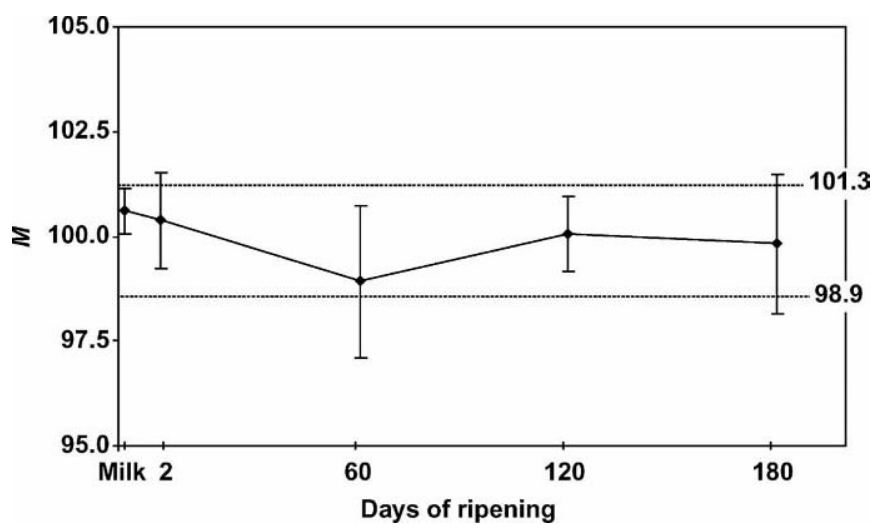

Figure 3. Values of $M$ calculated by substituting the triacylglycerol (TAG) composition values for milk and Manchego cheeses during ripening into Equation 2 for ewe milk fat proposed in our laboratory. Bold values along the y-axis (dotted lines) refer to the confidence range of the equation. Error bars represent standard deviations $(\mathrm{n}=$ 6 for milk and 2-d cheeses; $\mathrm{n}=15$ for 60,120 , and $180 \mathrm{~d}$ of ripening).

$$
M=7.733 \times \mathrm{C} 40+2.428 \times \mathrm{C} 50+21.392 \times \mathrm{C} 52
$$

tion No. 213/2001, 2001), all of the milk and cheese samples from the 3 producers fit the equation quite well. The minimum and maximum $M$ values, 97.79 and 103.92 (Figure 2), were for different cheese manufacturing batches.

These results suggest that the equations may be useful in detecting foreign fats in Mahón cheeses during the ripening period studied, i.e., in determining the authenticity of the milk fat in PDO Mahón cheeses.

The $M$ mean values for Manchego cheese (Figure 3) also came within the interval reported for the TAG formula (Equation 2) for ovine milk (98.87 to 101.25; Goudjil et al., 2003), although certain individual values fell outside the range. At $2 \mathrm{~d}$ of ripening, $17 \%$ of the analytical values obtained were higher than the range, and the extreme value recorded was 102.4. At $60 \mathrm{~d}$ of ripening, $25 \%$ of the analytical values were lower than the range, most of them between 97.9 and 98.8 , and only one extreme value was located at 95.6. At $180 \mathrm{~d}$ of ripening, $33 \%$ of the analytical values were outside the limits, at both sides of the range; the higher value was 102.5, and the lower value was 97.6.

These results suggest that the proposed equation can also be used to test whether Manchego cheese samples are genuine over the study period, as the deviations from the acceptable interval were small. However, because the interval for the ewe's milk was very compact, rather more so than for the cow milk, several samples from the cheese under consideration should be analyzed before any opinion as to sample origin is ventured.

In a study of different bovine cheeses, Battelli and Pellegrino (1994) observed that changes in the TAG composition did not become significant while FFA levels were $<15 \mathrm{mmol} / 100 \mathrm{~g}$ of cheese, which meant that the regression equation proposed by the European Union could be used to check sample authenticity. The results of the present study are in consonance with that finding, as FFA levels attained in these 2 PDO cheeses were appreciably below the level cited in that paper.

\section{CONCLUSIONS}

The TAG composition by CN of 2 PDO cheeses, Mahón and Manchego, showed small differences among producers. Moreover, the changes in TAG composition during ripening were not statistically significant, according with the low level of lipolysis.

In Mahón cheese, all of the milk and cheese samples from the 3 producers fit the equation. As a consequence, the obtained results suggest that the European Union equation may be useful for detecting foreign fats in this cheese. Nevertheless, in Manchego cheese, because of the thin interval established for ewe milk, a high number of samples to analyze would be needed before a 
decision about the authenticity of cheese fat could be determined.

\section{ACKNOWLEDGMENTS}

The authors are grateful to the DPO of Mahón and Manchego cheeses for their collaboration in development of this project. This work was supported by the Research Projects CAL01-013 and AGL2003-01712.

\section{REFERENCES}

Banfi, S., and M. Bergna. 1999. Programmable temperature vaporizer (PTV) applied to the triglyceride analysis of milk fat. J. High Resol. Chromatogr. 22:93-96.

Battelli, G., and L. Pellegrino. 1994. Detection of non-dairy fat in cheese by gas chromatography of triglycerides. Ital. J. Food Sci. 6:407-419.

Collins, I. F., P. L. H. McSweeney, and M. G. Wilkinson. 2003. Lipolysis and free fatty acid catabolism in cheese: A review of current knowledge. Int. Dairy J. 13:841-866.

Contarini, G., and P. M. Toppino. 1995. Lipolysis in Gorgonzola cheese during ripening. Int. Dairy J. 5:141-155.

EU Commission Regulation No. 213/2001. 2001. Methods for the analysis and quality evaluation of milk and milk products. Commission Regulation (EC) No. 213/01 of 9 January. Offic. J. Eur. Commun. L37:42-99.

Fontecha, J., V. Díaz, M. J. Fraga, and M. Juárez. 1998. Triglyceride analysis by gas chromatography in assessment of authenticity of goat milk fat. J. Am. Oil Chem. Soc. 75:1893-1896.

Fuente, M. A., J. Fontecha, and M. Juárez. 1993. Fatty-acid composition of the triglyceride and free fatty acid fractions in different cows, ewes and goats milk cheeses. Z. Lebensm. Unters. Forsch. 196:155-158.

Fuente, M. A., and M. Juárez. 2005. Authenticity assessment of dairy products. Crit. Rev. Food Sci. Nutr. 45:563-585.

González, R., S. Sifre, J. Benedito, and V. Nogue. 2002. Comparison of electromyographic pattern of sensory experts and untrained subjects during chewing of Mahón cheese. J. Dairy Res. 69:151-161.

Goudjil, H., J. Fontecha, M. J. Fraga, and M. Juárez. 2003. TAG composition of ewe's milk fat. Detection of foreign fats. J. Am. Oil Chem. Soc. 80:219-222.
ISO-IDF. 2001. Milk and milk products-Extraction methods for lipids and liposoluble compounds. ISO International Standard. 14156-IDF 172:2001.

Juárez, M. 1990. Tests for fraudulent identification. Pages 1285-1300 in Proc. XXIII Int. Dairy Congr., Montreal, Canada. Mutualpress, Montreal, Canada.

Juárez, M., M. A. De la Fuente, and J. Fontecha. 1992. Improved gas chromatographic method for determining the individual free fatty acids in cheese using a capillary column and a PTV injector. Chromatographia 33:351-356.

McSweeney, P. 2004. Biochemistry of cheese ripening. Int. J. Dairy Technol. 57:127-144.

Molkentin, J., and D. Precht. 2000. Equivalence of packed and capillary GC columns for detection of foreign fat in butter by use of the triglyceride formula method. Chromatographia 52:791-797.

Nájera, A. I., Y. Barcina, M. de Renobales, and L. J. R. Barron. 1998a. Influence of traditional smoking on the triglyceride composition during the ripening of Idiazábal cheese. Z. Lebensm. Unters. Forsch. 207:197-201.

Nájera, A. I., Y. Barcina, M. de Renobales, and L. J. R. Barron. 1998b. Changes in triacylglycerols during the ripening of Idiazábal cheese. J. Agric. Food Chem. 46:3252-3256.

Naviglio, D., and C. Raia. 2003. Application of a HRGC method on capillary column RTX 65-TG for triglyceride analysis to monitor butter purity. Anal. Lett. 36:3063-3094.

Partidario, A. M., M. Barbosa, and L. Vilas Boas. 1998. Free fatty acids, triglycerides and volatile compounds in Serra da Estrela cheese. Changes throughout ripening. Int. Dairy J. 8:873-881.

Pavía, M., A. J. Trujillo, E. Sendra, B. Guamis, and V. Ferragut. 2000. Free fatty acid content of Manchego-type cheese salted by brine vacuum impregnation. Int. Dairy J. 10:563-568.

Poveda, J. M., M. S. Pérez-Coello, and L. Cabezas. 1999. Evolution of the free fatty acid fraction in Manchego cheese during ripening. Milchwissenschaft 54:685-687.

Povolo, M., E. Bonfitto, G. Contarini, and P. M. Toppino. 1999. Study on the performance of three different capillary gas chromatographic analyses in the evaluation of milk fat purity. High Resol. J. Chromatogr. 22:97-102.

Precht, D. 1992a. Detection of foreign fat in milk fat. I. Qualitative detection by triacylglycerol formulae. Z. Lebens. Unters. Forsch. 194:1-8.

Precht, D. 1992b. Detection of foreign fat in milk fat. II. Quantitative evaluation of foreign fat mixtures. Z. Lebens. Unters. Forsch. 194:107-114.

Timms, R. E. 1980. Detection and quantification of non-milk fat in mixtures of milk and non-milk fats. J. Dairy Res. 47:295-303. 